\title{
Progress and opportunities for monitoring greenhouse gases fluxes in Mexican ecosystems: the MexFlux network
}

\author{
R. VARGAS, ${ }^{1,2}$ E. A. YÉPEZ, ${ }^{3}$ J. L. ANDRADE, ${ }^{4}$ G. ÁNGELES,${ }^{5}$ T. ARREDONDO, ${ }^{6}$ \\ A. E. CASTELLANOS,${ }^{7}$ J. DELGADO-BALBUENA, ${ }^{6}$ J. GARATUZA-PAYÁN,${ }^{3}$ \\ E. GONZÁLEZ DEL CASTILLO, ${ }^{8}$ W. OECHEL, ${ }^{9}$ J. C. RODRÍGUEZ,${ }^{7}$ A. SÁNCHEZ-AZOFEIFA, ${ }^{10}$ \\ E. VELASCO, ${ }^{11}$ E. R. VIVONI ${ }^{12}$ and C. WATTS ${ }^{7}$
}
${ }^{1}$ Centro de Investigación Cientifica y de Educación Superior de Ensenada, Carretera Ensenada-Tijuana 3918, Zona Playitas, 22860 Ensenada, Baja California, México
${ }^{2}$ Department of Plant and Soil Sciences, Delaware Environmental Institute, University of Delaware, 531 South College Ave., Newark, DE 19716, USA
${ }^{3}$ Instituto Tecnológico de Sonora, 5 de Febrero Sur 818, Centro, 85000 Ciudad Obregón, México
${ }^{4}$ Centro de Investigación Científica de Yucatán, Calle 43 núm. 130, Col. Chuburná de Hidalgo, 97200 Mérida, Yucatán, México
${ }^{5}$ Colegio de Postgraduados, Carretera México-Texcoco Km. 36.5, Montecillo, 56230 Texcoco, Estado de México
${ }^{6}$ Instituto Potosino de Investigación Científica y Tecnológica, Camino a la Presa de San José 2055, Lomas 4a. Sección, 78216 San Luis Potosí, México
${ }^{7}$ Universidad de Sonora, Blvd. Luis Encinas y Rosales s/n, Col. Centro, 83000 Hermosillo, Sonora, México
${ }^{8}$ University of California-Davis, 1 Shields Ave, Davis, CA 95616, USA
${ }^{9}$ San Diego State University, Campanile Dr. San Diego, CA 92182, USA
${ }^{10}$ Department of Earth and Atmospheric Sciences, University of Alberta, 1-26 Earth Sciences Building, Edmonton, T6G 2E3 Alberta, Canada
${ }^{11}$ CENSAM, Singapore-MIT Alliance for Research and Technology, 1 CREATE Way, \#09-03 CREATE Tower, Singapore 138602
${ }^{12}$ School of Earth and Space Exploration, Arizona State University, Tempe, AZ 85287, USA

Corresponding author: R. Vargas; e-mail: rvargas@udel.edu

Received March 15, 2012; accepted September 4, 2012

\section{RESUMEN}

Para entender los procesos de los ecosistemas desde un punto de vista funcional es fundamental entender las relaciones entre la variabilidad climática, los ciclos biogeoquímicos y las interacciones superficie-atmósfera. En las últimas décadas se ha aplicado de manera creciente el método de covarianza de flujos turbulentos (EC, por sus siglas en inglés) en ecosistemas terrestres, marinos y urbanos para medir los flujos de gases de invernadero (p. ej., $\mathrm{CO}_{2}, \mathrm{H}_{2} \mathrm{O}$ ) y energía (p. ej., calor sensible y latente). En diversas regiones se han establecido redes de sistemas EC que han aportado información científica para el diseño de políticas ambientales y de adaptación. En este contexto, el presente trabajo delimita el marco conceptual y técnico para el establecimiento de una red regional de medición de flujos de gases de efecto invernadero en México, denominada MexFlux, cuyo objetivo principal es mejorar nuestra comprensión de la forma en que la variabilidad climática y la transformación ambiental influye en la dinámica de los ecosistemas mexicanos ante los factores de cambio ambiental global. En este documento se analiza primero la importancia del intercambio de $\mathrm{CO}_{2}$ y vapor de agua entre los ecosistemas terrestres y la atmósfera. Después se describe brevemente la técnica de covarianza de flujos turbulentos para la medición de éstos, y se presentan ejemplos de mediciones en dos ecosistemas terrestres y uno urbano en México. Por último, se describen las bases conceptuales y operativas a corto, mediano y largo plazo para la continuidad de la red MexFlux. 


\section{ABSTRACT}

Understanding ecosystem processes from a functional point of view is essential to study relationships among climate variability, biogeochemical cycles, and surface-atmosphere interactions. Increasingly during the last decades, the eddy covariance (EC) method has been applied in terrestrial, marine and urban ecosystems to quantify fluxes of greenhouse gases (e.g., $\left.\mathrm{CO}_{2}, \mathrm{H}_{2} \mathrm{O}\right)$ and energy (e.g., sensible and latent heat). Networks of EC systems have been established in different regions and have provided scientific information that has been used for designing environmental and adaptation policies. In this context, this article outlines the conceptual and technical framework for the establishment of an EC regional network (i.e., MexFlux) to measure the surface-atmosphere exchange of heat and greenhouse gases in Mexico. The goal of the network is to improve our understanding of how climate variability and environmental change influence the dynamics of Mexican ecosystems. First, we discuss the relevance of $\mathrm{CO}_{2}$ and water vapor exchange between terrestrial ecosystems and the atmosphere. Second, we briefly describe the EC basis and present examples of measurements in terrestrial and urban ecosystems of Mexico. Finally, we describe the conceptual and operational goals at short-, medium-, and long-term scales for continuity of the MexFlux network.

Keywords: Environmental networks, eddy covariance, FLUXNET, greenhouse gases, long-term measurements, surface-air exchange.

\section{Introduction}

Humankind faces new challenges to develop policies for the reduction, adaptation and mitigation of global environmental change. The scientific community has the responsibility of providing information to enable the development of such policies and strategies. This includes the generation of knowledge about the components, processes and mechanisms by which ecosystems respond to: (1) climate variability, and (2) the interaction and effects of greenhouse gases (e.g., $\mathrm{CO}_{2}, \mathrm{CH}_{4}, \mathrm{~N}_{2} \mathrm{O}$ ) on global climate.

From a functional standpoint, the interaction between climate variability, vegetation dynamics (e.g., land use change), and biogeochemical cycles are necessary to understand ecosystem processes within the context of global environmental change (Chapin et al., 2002). From a socio-ecological point of view, the water and carbon cycles are critical for the regulation and supporting of ecosystem services, and therefore represent part of our natural capital (Millennium Ecosystem Assessment, 2005). Thus, it is important to: (1) evaluate the influence of these processes on atmospheric dynamics, (2) estimate the potential ecosystem services provided to human populations, and (3) provide relevant information to define policies for management and conservation.

Through the processes of photosynthesis and respiration, ecosystems play a key role in the capture and emission of $\mathrm{CO}_{2}$ (Fig. 1). Furthermore, the characteristics of vegetation cover also affect water vapor fluxes into the atmosphere through evapotranspiration (Fig. 1), and therefore the balance between sensible and latent heat fluxes that impact the atmosphere (Fisher et al., 2011). Additionally, the type and extent of vegetation defines the physical properties, such as surface albedo, emissivity and aerodynamic roughness that can affect air temperature, precipitation, and wind speed (Burba and Verma, 2005). In turn, climate is the main factor determining the presence and distribution of ecosystems around the world, and establishes complex feedbacks between the biosphere and global biogeochemical cycles (Bonan, 2008; Heimann and Reichstein, 2008).

Current knowledge on the interactions between climate and carbon and water cycles is still limited. This has been identified by the Intergovernmental Panel on Climate Change (IPCC) as a "key uncertainty" in our understanding of present and future climate (IPCC, 2007). The experimental evaluation of the interaction between weather and these cycles has made significant progress with the development of new methodologies to measure the mass (e.g., water vapor, $\mathrm{CO}_{2}$ ) and energy exchange (e.g., sensible heat, solar radiation) at multiple spatial and temporal scales (Canadell et al., 2000). This development has required a multidisciplinary link between earth and atmospheric sciences, functional ecology, biogeochemistry, and mathematics, which has improved the application of model-data fusion (Vargas et al., 2011a). This scientific development, known as the third scientific paradigm, is complemented by the integration of knowledge from computer systems science, which is emerging as the fourth paradigm in scientific research (Hey et al., 2009). 


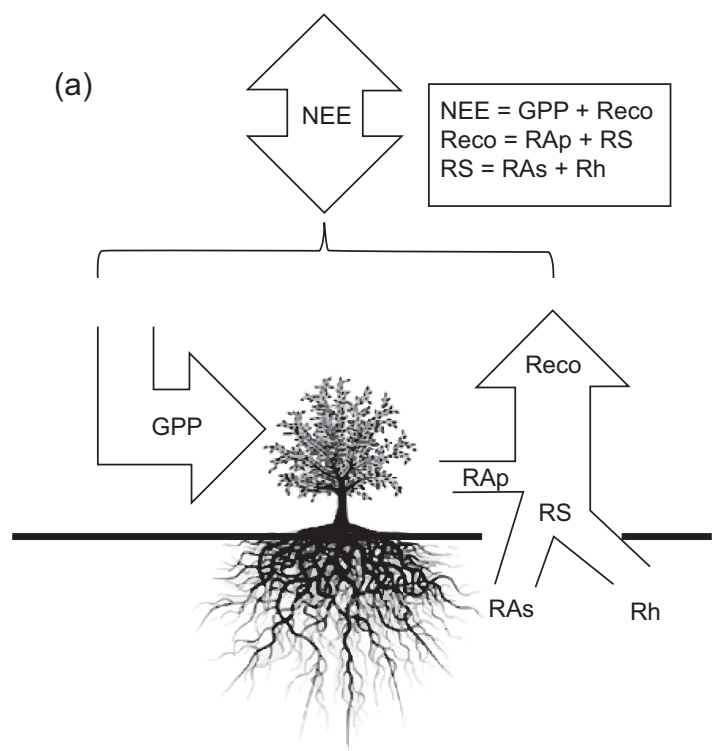

(b)

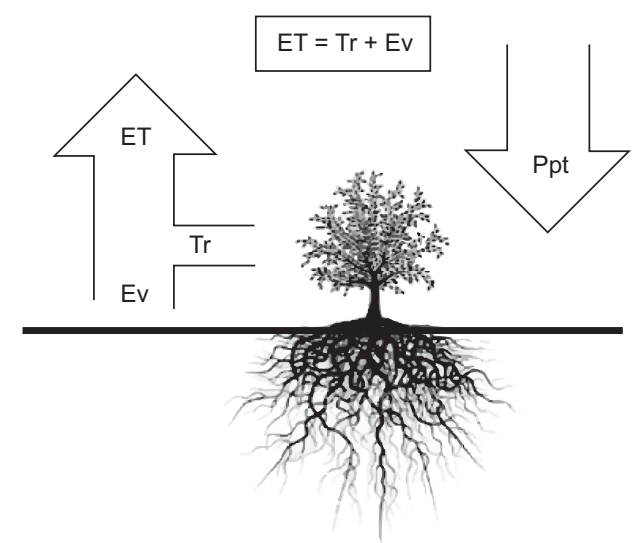

Fig. 1. Main vertical fluxes of carbon and water vapor in terrestrial ecosystems. (a) Carbon net ecosystem exchange (NEE), gross primary production (GPP), ecosystem respiration (Reco), plant respiration (RAp), soil respiration (RS), autotrophic soil respiration (RAs), and heterotrophic soil respiration (Rh). (b) Water vapor flows: evapotranspiration (ET), soil evaporation (Ev), vegetation transpiration (Tr) and the vertical water input by precipitation $(\mathrm{Ppt})$.

During the last decades, several networks for monitoring ecosystem processes and attributes have been established (e.g., International Long Term Ecological Research Network, [ILTER], and Human and Biophysical Dimensions of Tropical Dry Forests in the Americas [Tropi-Dry], among others). These networks have standardized experimental protocols, which have allowed collecting a large amount of information and created regional synthesis reports (Greenland et al., 2003). Another example is FLUXNET - the global network for flux measurements of water vapor, $\mathrm{CO}_{2}$, and energy in terrestrial ecosystems (Baldocchi et al., 2001). This network incorporates more than 500 study sites around the world, which have been used for the analysis of ecosystem primary productivity, evapotranspiration, and the response of ecosystems to disturbances (Baldocchi, 2008). FLUXNET is considered a network of networks that consists of several regional networks (e.g., AmeriFlux in the United States of America, CarboEurope in Europe). Despite its broad coverage, FLUXNET sites are mainly located in temperate ecosystems, with annual temperatures between 5 and $17{ }^{\circ} \mathrm{C}$, annual rainfall between 600 and $1250 \mathrm{~mm}$, and latitudes above $30^{\circ} \mathrm{N}$.
Similarly, in recent years new sites for monitoring $\mathrm{CO}_{2}$ and energy fluxes to the atmosphere have been established at various urban locations (i.e., Urban Flux Network). The number of sites in this network is still much lower than those for FLUXNET with $\sim 30$ sites of which only 20 are active and only two correspond to sub-tropical cities. Importantly, more than $70 \%$ of $\mathrm{CO}_{2}$ emissions of anthropogenic origin occurs in cities, despite occupying only $2 \%$ of the total land area (Le Quéré et al., 2009).

The time is ripe for the establishment of a Mexican eddy covariance (EC) network for several reasons. First, long-term impact of land use change and anthropogenic changes in biogeography have fragmented and fundamentally transformed Mexican landscapes. These transformations have created a highly heterogeneous vegetation cover forming complex landscape mosaics that differ in plant cover, age, plant species, and functional group composition over a wide range of spatial scales (Mittermeier and Goettsch, 1997). Second, arid/ semiarid and tropical ecosystems are underrepresented in FLUXNET (Baldocchi, 2008). This is of particular relevance for Mexico because over $60 \%$ of its territory is represented by arid and semiarid ecosystems located below the $30^{\circ} \mathrm{N}$ latitude (Chal- 
Table I. Major scientific questions that MexFlux will answer.

1. What are the exchange magnitudes of water vapor, energy, $\mathrm{CO}_{2}, \mathrm{CH}_{4}, \mathrm{~N}_{2} \mathrm{O}$ in terrestrial, coastal, marine and urban ecosystems of Mexico?

2. What is the spatial and temporal variability of these fluxes?

3. What are the mechanisms that regulate the exchange of greenhouse gases and energy for different types of ecosystems?

4. How do disturbances and extreme climate events (e.g., land use change, droughts, hurricanes, fires) influence the exchange of energy and greenhouse gases in the different Mexican ecosystems?

5. What is the influence of biological diversity in the magnitude of fluxes and stores of matter and energy?

6. Is there a functional interaction between the type of organisms and abiotic components of the ecosystem?

7. What are the recommended mitigation strategies to reduce emissions of greenhouse gases in natural and urban ecosystems?

lenger and Soberón, 2008). Furthermore, tropical ecosystems located in Mexico are highly productive and subject to natural disturbances (e.g., hurricanes) that substantially influence ecosystem fluxes magnitudes and variances (Vargas, 2012). Third, Mexico is experiencing large human migration from rural areas to urban centers, which will influence the longterm dynamics of natural and urban ecosystems. Thus, the establishment of new flux measurement sites in Mexico will broaden the representativeness of worldwide flux networks, and will increase our knowledge of ecosystem dynamics under seasonal warm-dry and warm-wet conditions.

The objective of this work is to outline a conceptual framework for the establishment of a regional network for monitoring greenhouse gases fluxes in Mexico: the MexFlux network. The principal goal of this network is to generate scientific knowledge to understand the dynamics and role of Mexican ecosystems within the context of global environmental change (Tables I and II). This network will provide the scientific basis for public policy to reduce emissions, adaptation/mitigation to environmental change and early detection of environmental hazards (e.g., loss of habitat/biodiversity, extreme weather events). This manuscript addresses the following issues: (1) description of $\mathrm{CO}_{2}$ and water vapor fluxes from terrestrial ecosystems, (2) the EC technique for measuring these fluxes, and (3) the conceptual and operational goals at short-, medium- and longterm scales for permanent operation of the MexFlux network.

\section{Main $\mathrm{CO}_{2}$ and water vapor fluxes in terrestrial ecosystems}

The main carbon fluxes consist essentially of gains and losses of $\mathrm{CO}_{2}$ in ecosystems (Chapin et al., 2002) (Fig. 1). The total amount of carbon incorporated into the ecosystem through photosynthesis is known as gross primary production (GPP), and it is estimated that the global GPP average is about $123 \mathrm{PgCyr}^{-1}$ (Beer et al., 2010). A proportion of $\mathrm{CO}_{2}$

Table II. Specific objectives for the MexFlux network.

1. To quantify the spatial and temporal variation of carbon storage and exchange of greenhouse gases and energy in the main terrestrial, coastal, marine and urban ecosystems of Mexico.

2. To understand the mechanisms that regulate the dynamics of greenhouse gases from ecosystems as well as the biogeochemical cycles of carbon, water and nitrogen through observational and manipulative experiments, and models of ecosystem processes.

3. To understand the mechanisms that control the energy partitioning in representative ecosystems of Mexico through observations, experiments and models.

4. To build a high quality historical database for site-level analysis, and data-synthesis activities at regional and global scales.

5. To support and guide the individual efforts of new researchers interested in establishing new monitoring sites and methods for quantifying carbon stocks and fluxes of greenhouse gases and energy.

6. To establish standardized protocols for measurements, calibration, data processing, data archiving, and data sharing, in order to provide value added products for research and policymaking. 
captured by ecosystems returns to the atmosphere via ecosystem respiration (Reco). The balance between $\mathrm{CO}_{2}$ captured via GPP and loss through Reco is the net ecosystem exchange (NEE), which ultimately determines if the ecosystem is a net carbon source or sink (Fig. 1). The NEE represents the total $\mathrm{CO}_{2}$ exchanged vertically between land-surface and the atmosphere, and can be directly measured using the micrometeorological technique of EC (Aubinet et al., 2000; Baldocchi, 2003).

Furthermore, Reco components include the emission of $\mathrm{CO}_{2}$ from soils (Vargas et al., 2011a) known as total soil respiration (RS), and to a lesser extent by autotrophic respiration of leaves and stems of plants (RAp, Fig. 1). RS results from the production of $\mathrm{CO}_{2}$ by heterotrophic organisms (i.e., heterotrophic respiration, $\mathrm{Rh}$ ) and autotrophic respiration (RAs, production of $\mathrm{CO}_{2}$ by plant roots and organisms directly associated with the rhizosphere) (Hanson et al., 2000). Although we can identify the components that contribute for the ecosystem carbon balance, methodological uncertainties still exist. For example, to date there is no theoretical model to represent the biophysical mechanisms that regulate the temporal and spatial variation of RS (Bond-Lamberty and Thomson, 2010; Vargas et al., 2011a). One complication arises from the uncertainty in the estimation of RS as it varies throughout the year (Mahecha et al., 2010) due to the heterogeneity of the contributions by RAs and Rh under different soil and environmental conditions.

Evapotranspiration (ET) is the sum of water transferred from the Earth's surface to the atmosphere through evaporation (Ev) and plant transpiration $(\mathrm{Tr}$, Fig. 1) (Fisher et al., 2011). Evaporation comprises the movement of water into the atmosphere from soil, plant surfaces and water bodies. The transport of water from the surface to the atmosphere through evaporation and transpiration constitutes up to $75 \%$ of the total energy transfer on the planet (Jung et al., 2010). These processes are closely related to GPP, since the opening of stomata during photosynthesis is inevitably accompanied by water loss through transpiration, while the residence time of water in the soil largely controls the rate of decomposition of organic matter and consequently RS (Yepez and Williams, 2009). Therefore, it is critical to understand the coupling between the biophysical processes that regulate the magnitude of $\mathrm{CO}_{2}$ and water vapor fluxes in time and space across ecosystems.

\section{Eddy covariance (EC) technique}

The energy and mass exchange between the biosphere and atmosphere can be studied through different methods depending on the characteristics of the ecosystem and the spatial and temporal scales of interest (Canadell et al., 2000). At the scale of experimental plots (i.e., square meters), gas exchange chambers provide information on microbial and plant ecophysiological processes that control the exchange of water vapor and $\mathrm{CO}_{2}$ (Vargas et al., 2011a). However, the spatial sampling is limited, making it difficult to extrapolate results to larger spatial scales, and undesirable effects of confinement and manipulation may also be inherent to the methodology (Pumpanen et al., 2004). For scales between 100 to $1000 \mathrm{~m}^{2}$ (which are most representative of an ecosystem) micrometeorological techniques are a useful approach to monitor ecosystem exchange processes of water vapor, $\mathrm{CO}_{2}$, other biogenic gases, and aerosols. Among micrometeorological techniques, the EC has been the most widely used for estimating NEE by direct measurement of vertical fluxes of mass and energy across a horizontal plane above the canopy (Aubinet et al., 2000; Baldocchi, 2003). This technique is in situ and non-destructive, and can be applied to time scales ranging from fractions of an hour to years; it is therefore ideal to capture the flux dynamics across different weather conditions from diurnal cycles to long-term environmental changes (Baldocchi, 2003). The technique is also suitable for understanding the response of ecosystems to disturbance, management history and comparative studies between ecosystem functional types, or for different successional stages (Baldocchi, 2008). However, its implementation is complex because the study site should be in a relatively flat terrain and be homogeneous in terms of vegetation and soil. The installation and operation of instruments, as well as processing and data analysis require special attention for correct results representing the ecosystem (Papale et al., 2006).

Briefly, turbulent exchanges of momentum, heat, water vapor, $\mathrm{CO}_{2}$, and in general any scalar, can be mathematically defined as the covariance between the instantaneous deviations or fluctuations of the scalar in question (e.g., temperature, concentration of water vapor or $\mathrm{CO}_{2}$ mixing ratio) and vertical wind velocity over a specific time interval (e.g., $30 \mathrm{~min}$ ). 
For example, the vertical turbulent flux of $\mathrm{CO}_{2}$ is defined as the covariance between the fluctuations of vertical wind speed and $\mathrm{CO}_{2}$ mass density ( $w^{\prime} c$ ') multiplied by the average air density $(\overline{\rho a})$ (Baldocchi, 2003). If the net flux is positive (i.e., towards the atmosphere) the ecosystem is a net source, but on the contrary if the flux is negative, then the ecosystem functions as a sink.

To monitor fluxes of greenhouse gases (GHGs) and energy using this technique, the installation of a micrometeorology tower with particular equipment located at a suitable height is required, to ensure the representativeness needed for the exchange surface in all directions. The height and position of the tower in turn depend on the height of the vegetation as well as the predominant wind direction and the average wind speed. A basic EC system to measure fluxes of $\mathrm{CO}_{2}$ consists of a three-dimensional sonic anemometer and a $\mathrm{CO}_{2}$ analytical sensor. Fast-response $\mathrm{CO}_{2}$ analyzers are based on the principle of absorption of infrared radiation by trace gases, and often measure $\mathrm{CO}_{2}$ and water vapor at the same time. Also an EC system includes basic equipment to measure hydrometeorological variables (e.g., precipitation, temperature, relative humidity, soil temperature and moisture), and the surface available energy (i.e., the net radiation, and ground heat flux). Several publications contain detailed descriptions of the EC method in terrestrial ecosystems (Goulden et al., 1996; Aubinet et al., 2000; Baldocchi, 2003) and cities (Velasco and Roth, 2010).

\section{The conceptual framework and operational MexFlux}

Current knowledge of the dynamics of carbon and water fluxes in Mexican ecosystems is very limited (Vargas et al., 2012a). Among the research published in peer-reviewed literature are RS measurements in tropical forests (Davidson et al., 1993; Vargas and Allen, 2008; Vargas, 2012), NEE from subtropical and semiarid ecosystems (Hastings et al., 2005; Pérez-Ruiz et al., 2010) and in urban areas of Mexico City (Velasco et al., 2005, 2009, 2011), and ET in semiarid ecosystems (Watts et al., 2007; Vivoni et al., 2008). These measurements of energy, water vapor and $\mathrm{CO}_{2}$ fluxes in Mexican ecosystems originated from individual efforts, and unfortunately there is a lack of a strategic governmental program to ensure long-term funds for the establishment and continuity of these types of studies.

MexFlux is the network of flux measurements of GHGs and energy fluxes from terrestrial, urban,

Table III. Information relevant to the study sites in the MexFlux network.

\begin{tabular}{llccccc}
\hline Site name & $\begin{array}{l}\text { Location } \\
\text { (state) }\end{array}$ & $\begin{array}{c}\text { North } \\
\text { latitude }\end{array}$ & $\begin{array}{c}\text { West } \\
\text { longitude }\end{array}$ & $\begin{array}{c}\text { Elevation } \\
\text { (masl) }\end{array}$ & $\begin{array}{c}\text { Ecosystem } \\
\text { (type of vegetation) }\end{array}$ & $\begin{array}{c}\text { Start of } \\
\text { measurements }\end{array}$ \\
\hline La Paz & Baja California Sur & 24.13 & 110.43 & 170 & Arid shrubland & 2002 \\
Tesopaco & Sonora & 27.84 & 109.3 & 460 & Tropical dry forest & 2004 \\
Rayón & Sonora & 29.74 & 110.53 & 630 & Subtropical shrubland & 2004 \\
Mogor & Baja California & 32.07 & 116.62 & 406 & Subtropical shrubland & 2008 \\
Chamela & Jalisco & 19.51 & 105.04 & 52 & Tropical dry forest & 2007 \\
Sierra de los & & & & & & \\
Locos & Sonora & 29.96 & 110.46 & 1403 & Oak woodland & 2008 \\
Ojuelos & Jalisco & 21.79 & 101.61 & 2228 & Semiarid grassland & 2010 \\
Atopixco & Hidalgo & 20.62 & 110.6 & 2094 & Mixed oak-pine forest & 2012 \\
Colorada & Sonora & 28.7 & 110.54 & 398 & Arid rangeland & 2011 \\
Escandón & Distrito Federal & 19.4 & 99.18 & 2240 & Urban-residential- & $2011^{*}$ \\
& & & & & commercial & \\
Kaxil Kiuic & Yucatán & 28.08 & 89.57 & 114 & Tropical dry forest & 2011 \\
Todos Santos & Baja California & 31.81 & 116.8 & 4 & Ocean & $2008-2009^{* *}$ \\
\hline
\end{tabular}

masl: meters above sea level.

* During 2006 and 2008 fluxes were measured during intensive short-term studies (Velasco et al., 2009; Velasco et al., 2011).

** This tower measured fluxes from the ocean and was located at the Todos Santos island in front of Ensenada, Baja California (Reimer et al., in review). 
coastal and marine ecosystems in Mexico. Its main objective is to generate scientific knowledge about the role of the dynamics of Mexican ecosystems to global environmental change (Tables I and II). Mexico currently has 11 study sites using the EC technique and has over 30 site-years of data of water vapor and $\mathrm{CO}_{2}$ fluxes (Vargas et al., 2012a). A number of sites are of recent installation (i.e., established in 2011), while others have been operating between six and nine years (Table III). The sites with the longest continuous measurements are located in semiarid ecosystems of Baja California Sur (established in 2002) and Sonora (established in 2004). With regard to distribution, the sites are located at: semiarid shrubland in Baja California; oak woodland, subtropical, tropical dry forest and grassland in Sonora; tropical dry forest in Jalisco and Yucatán; shortgrass steppe in Jalisco; a managed pine forest in Hidalgo; and an urban residential/commercial site in Mexico City. Finally, a site was operated between 2008 and 2009 off the coast of Baja California measuring NEE over the ocean (Reimer et al., in review).

MexFlux brings together scientists interested in using the EC technique in ecosystems across Mexico. Up to two principal investigators represent each study site within MexFlux. These researchers are required to verify that the site follows the guidelines for measurement standardization to maintain proper functioning of the network and allow sites inter-comparisons. MexFlux members are working together towards standardization of data quality and a secure data management/analysis protocol. The network is intended to grow in coming years, as new sites will be established within strategic ecosystems to ensure the long-term operation of the network. The new sites, in addition to consistency with the assumptions for EC technique, should ideally be located at sites that represent the variability of Mexican ecosystems and/or at ecosystems and regions most vulnerable to environmental or land use change.

\section{Water vapor and $\mathrm{CO}_{2}$ fluxes in terrestrial eco- systems of Mexico}

Mexican ecosystems provide rich opportunities to validate previous observations across ecosystems. Some examples of relationships that could be tested and validated are those observed between phenology and $\mathrm{CO}_{2}$ fluxes (Richardson et al., 2010), control of GPP on RS (Vargas et al., 2011b), or the role of drought and water pulses (Thomey et al., 2011). What follows are examples from measurements at MexFlux sites to illustrate the diversity of patterns and magnitudes of $\mathrm{CO}_{2}$ fluxes.

For example, the Ojuelos site located in a semiarid grassland (Table III) is ideal for investigating the effect of precipitation pulses on NEE during the summer that result in higher $\mathrm{CO}_{2}$ emissions. Data from this site show that before precipitation events, nocturnal NEE values (Reco by definition) were $<$ $2 \mu \mathrm{mol} \mathrm{CO} \mathrm{CO}^{2} \mathrm{~s}^{-1}$ while after precipitation, pulses increased to values $>5 \mu \mathrm{mol} \mathrm{CO} \mathrm{CO}^{2} \mathrm{~s}^{-1}$ (Fig. 2). The implications of these observations rely on climate change scenarios characterized by changes in frequency and intensity of precipitation and pulses.

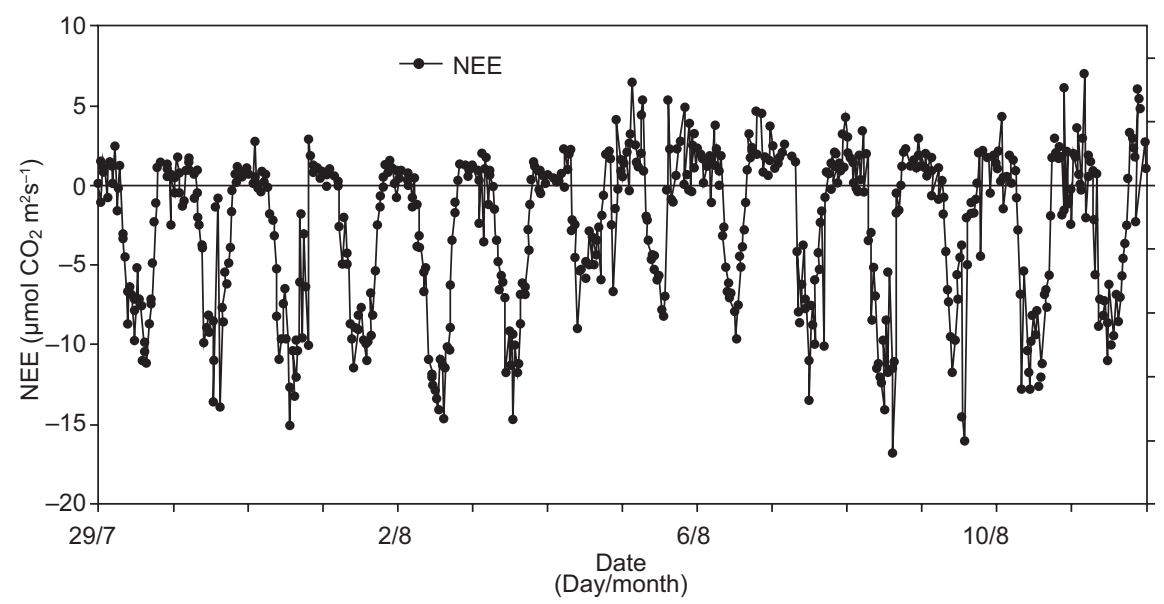

Fig. 2. Time series of half-hourly values of net ecosystem exchange (NEE) from a semiarid grassland at the Ojuelos site between July 29 and August 12, 2011. See Table III for site-specific information. 


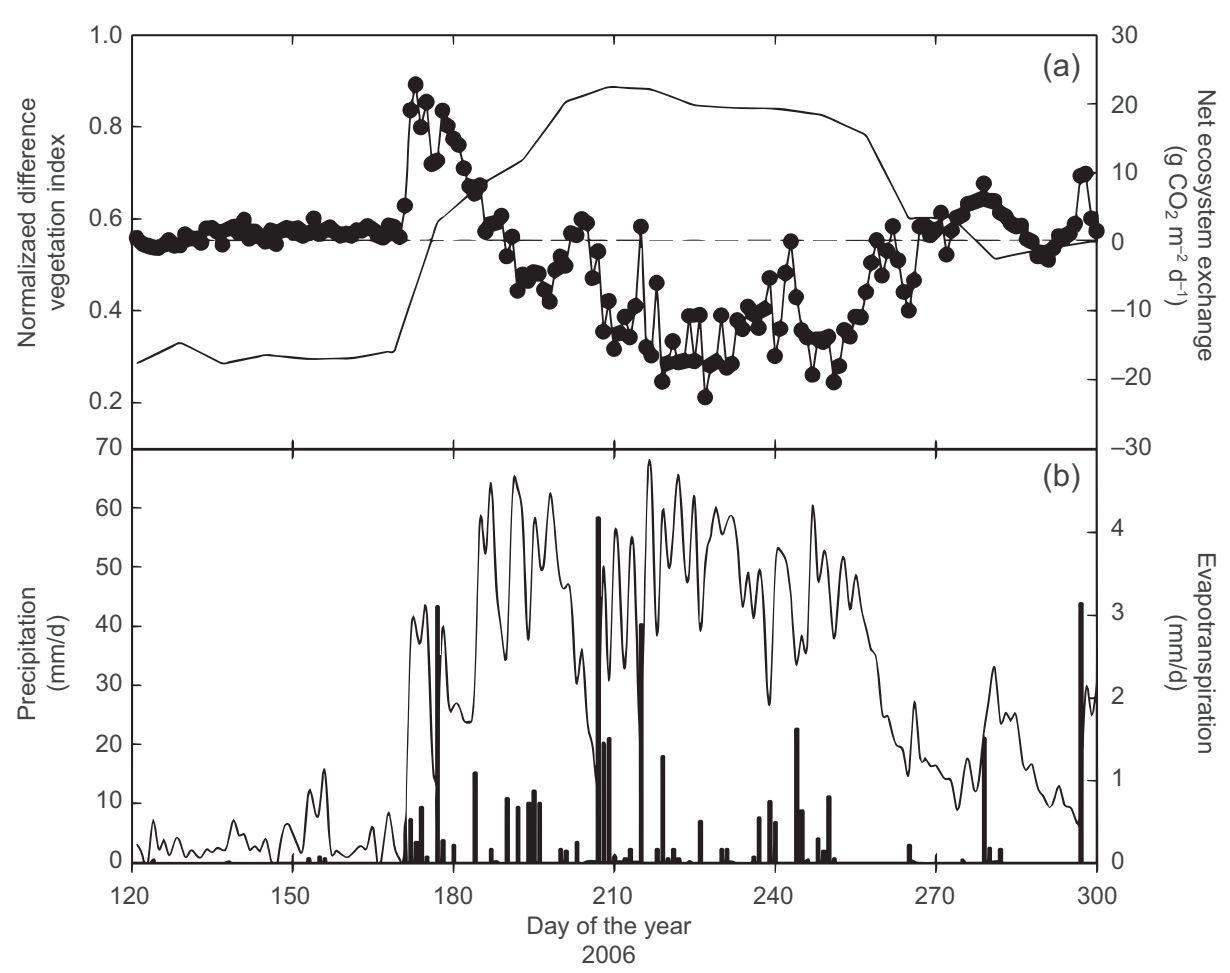

Fig. 3. Daily values showing the seasonal trend. (a) Rate normalized difference vegetation index (NDVI derived from MODIS observations) and net ecosystem exchange (NEE). (b) Evapotranspiration (ET) and precipitation at the study site Tesopaco; lowland deciduous in northwestern Mexico during the monsoon season of 2006 (PérezRuiz et al., 2010).

These changes in precipitation patterns can substantially affect carbon sequestration in semiarid rangelands by reducing or increasing water stress within the ecosystem (Thomey et al., 2011, Vargas et al., 2012b).

Another example comes from studying the North American Monsoon, which is a regional phenomenon that provides most of the annual rainfall over large areas of northern Mexico (Vivoni et al., 2010). Data from the Tesopaco site, a tropical deciduous forest (Table III) shows the influence of the monsoon over the seasonal trend of the normalized difference vegetation index (NDVI derived from MODIS observations), NEE and ET (Fig. 3), as a marked variability in the direction and magnitude of fluxes across the growing season. It is estimated that this forest can sequester up to $374 \mathrm{~g} \mathrm{CO}_{2} \mathrm{~m}^{-2}$ during the monsoon season (Pérez-Ruiz et al., 2010).

In urban sites, $\mathrm{CO}_{2}$ flux measurements have been used to evaluate emission inventories and develop mitigation strategies, while energy fluxes can be useful for urbanization planning through a better understanding of urban climatology (e.g., urban heat island). For example, Figure 4 compares the average diurnal $\mathrm{CO}_{2}$ flux measured using eddy covariance during a short study over the Escandón district in Mexico City with emission profiles extracted from the local emissions inventory (Velasco et al., 2009, 2011). It is noteworthy that the $\mathrm{CO}_{2}$ emission sources in urban ecosystems can be much more diverse than in natural ecosystems and their analysis requires a detailed interpretation of the measured fluxes (Fig. 4).

\section{MexFlux short- and long-term goals}

It is essential to strengthen collaborations among research groups for a successful coordination and operation of MexFlux. The network will use a strategy based on the coordination and combination of micrometeorological techniques, meteorological, remote sensing, biophysical and ecosystems-process modeling to obtain the best possible estimates of the GHG flux dynamics. In order to scale these measurements in time and space, it is essential to: (1) generate a standardized protocol for inter-calibration of 


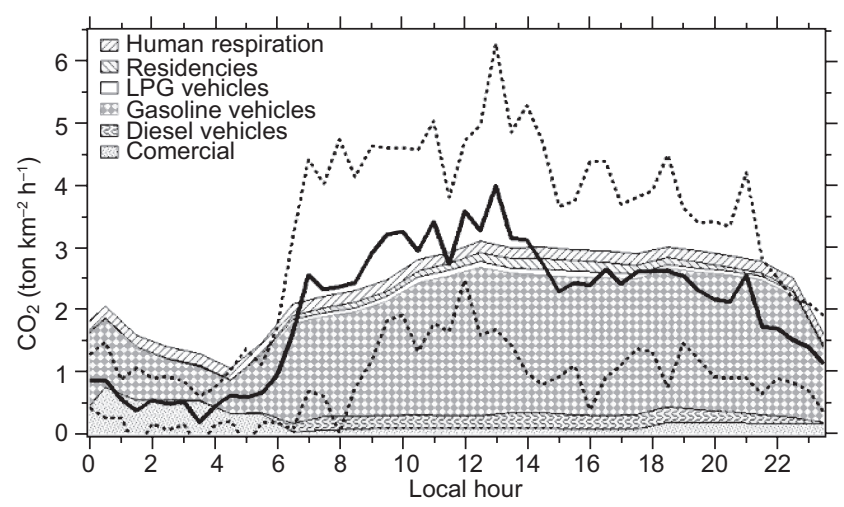

Fig. 4. Diurnal variations of $\mathrm{CO}_{2}$ emissions by source type in Escandón district (Mexico City emissions inventory taken from the Secretaría del Medio Ambiente del Gobierno del Distrito Federal (SMAGDF, 2008). The contribution by human breath was calculated as the product of the per capita ratio of respiration, the average concentration of $\mathrm{CO}_{2}$ in exhaled air and population density. The black line represents the average flux measured by eddy covariance, and the dotted lines indicate \pm 1 standard deviation of the measured flux (Velasco et al., 2009).

measuring instruments and measurement methods; and (2) develop quality assurance and control (QA/ QC) procedures of raw data and post-processing of computed fluxes (i.e., gap-filling series, partition NEE into GPP and RS). This QA/QC must comply with international standards (Papale et al., 2006) to generate useful and consistent datasets for regional and global synthesis studies.

To facilitate synthesis studies and maximize data use, the data storage and standardized post-processing could be provided by existing cyberinfrastructure in different institutions of MexFlux members (e.g., University of Alberta, Canada with its Enviro-Net platform). Initially, a specific MexFlux database will contain the products of site-level measurements (i.e., raw data) along with the processed data obtained following standardized protocols (Papale et al., 2006). MexFlux has adopted a policy of submitting information from each study site to this database within a period of one year from its incorporation to the network. Only principal investigators will submit raw and processed data, and these will be freely available to the network members, under a fair use policy. Finally, MexFlux will promote training of human resources in the area of micrometeorological and biophysical measurements of energy and GHG fluxes.
The short-term challenges facing MexFlux are: (1) developing protocols and standardization among sites for reducing uncertainties in the flux measurements; (2) establishing rules for archiving and processing data within the MexFlux database; (3) establishing clear and fair use data policies for all members according to the funding source for each project (i.e., domestic agencies and international funding); and (4) the study sites must invest in measuring a common set of biological and physical parameters to describe the ecosystem (e.g., vegetation structure, phenology, soil properties, management history) to better interpret observed fluxes (Law et al., 2008).

In the long-term, MexFlux needs a continuous interaction with institutions and networks at the national and international levels. Important collaborations have been identified with the scientific networks sponsored by the Consejo Nacional de Ciencia y Tecnología (Conacyt) such as the Red Temática del Agua (RETAC, water research network), Red Temática de Ecosistemas (EcoRed, ecosystems research network), and Red Temática de Medio Ambiente y Sustentabilidad (REMAS, environmental sustainability research network). Additionally, there is a strong link with the Programa Mexicano del Carbono (PMC, Mexican carbon program), the Red Mexicana de Investigación Ecológica a Largo Plazo (Mex-LTER, Mexican long- 
term ecological research network), and international networks such as the North American Carbon Program (CarboNA), and Tropi-Dry. MexFlux is expected to have a fundamental role within FLUXNET since Mexican ecosystems are underrepresented and this limits the production of synthesis studies across regions, which are important for scientific understanding and policy-making across North America (Harmon et al., 2011; Masek et al., 2011; Vargas et al., 2012a).

We also suggest that long-term measurements within MexFlux should incorporate other GHGs, pollutants, aerosols and stable isotopes as technology becomes more accessible and more scientists join the network. This new information could be integrated into models of ecosystem processes to update and validate previous observations and parameters. MexFlux's long-term challenge is to seek the integration of researchers in fields of climate modeling, mathematics, biogeochemistry, and social science related to policy making. Finally, we believe that it is essential to develop multi-institutional training and financing mechanisms for the maintenance and operation of the study sites and secure the continuity of MexFlux. This will only be achieved if there is political will and evidence of the usefulness of value added products from the network for policy-making and scientific advancement.

\section{Acknowledgements}

The authors acknowledge funding from Conacyt (EcoRed-Conacyt) for meetings that have facilitated discussions between researchers and students. $\mathrm{RV}$ is grateful for funding from Conacyt (Ciencia Básica-152671). TA and CW thanks SEP-Conacyt. ASA and EGC thank the Inter-American Institute for Global Change Research, Tropi-Dry, supported by the National Science Foundation. EGC also acknowledges funding from a Conacyt-UC Mexus scholarship. CW gratefully acknowledges funding from Conacyt Ciencia Básica. EV acknowledges support from INE, MCE2, SMA-GDF and Singapore National Research Foundation trough SMART. GA and JLA acknowledge support from USAID and USFS.

\section{References}

Aubinet M., A. Grelle, A. Ibrom, U. Rannik, J. Moncrieff, T. Foken, A. S. Kowalski, P. H. Martin, P. Berbigier, C. Bernhofer, R. Clement, J. Elbers, A. Granier, T. Grunwald, K. Morgenstern, K. Pilegaard, C. Reb- mann, W. Snijders, R. Valentini and T. Vesala, 2000. Estimates of the annual net carbon and water exchange of forests: The EuroFlux methodology. Adv. Ecol. Res. 30, 113-175.

Baldocchi D., E. Falge, L. H. Gu, R. Olson, D. Hollinger, S. Running, P. Anthoni, C. Bernhofer, K. Davis, R. Evans, J. Fuentes, A. Goldstein, G. Katul, B. Law, X. H. Lee, Y. Malhi, T. Meyers, W. Munger, W. Oechel, K. T. Paw, K. Pilegaard, H. P. Schmid, R. Valentini, S. Verma, T. Vesala, K. Wilson, and S. Wofsy, 2001. FLUXNET: A new tool to study the temporal and spatial variability of ecosystem-scale carbon dioxide, water vapor, and energy flux densities. B. Am. Meteorol. Soc. 82, 2415-2434.

Baldocchi D. D., 2003. Assessing the eddy covariance technique for evaluating carbon dioxide exchange rates of ecosystems: Past, present and future. Glob. Change Biol. 9, 479-492.

Baldocchi D., 2008. Breathing of the terrestrial biosphere: lessons learned from a global network of carbon dioxide flux measurement systems. Aust. J. Bot. 56, 1-26.

Beer C., M. Reichstein, E. Tomelleri, P. Ciais, M. Jung, N. Carvalhais, C. Rodenbeck, M. A. Arain, D. Baldocchi, G. B. Bonan, A. Bondeau, A. Cescatti, G. Lasslop, A. Lindroth, M. Lomas, S. Luyssaert, H. Margolis, K. W. Oleson, O. Roupsard, E. Veenendaal, N. Viovy, C. Williams, F. I. Woodward and D. Papale, 2010. Terrestrial gross carbon dioxide uptake: Global distribution and covariation with climate. Science 329, 834-838.

Bonan G. B., 2008. Forests and climate change: Forcings, feedbacks, and the climate benefits of forests. Science 320, 1444-1449.

Bond-Lamberty B. and A. Thomson, 2010. Temperature-associated increases in the global soil respiration record. Nature 464, 579-582.

Burba G. G. and S. B. Verma, 2005. Seasonal and interannual variability in evapotranspiration of native tallgrass prairie and cultivated wheat ecosystems. Agr. Forest. Meteorol. 135, 190-201.

Canadell J. G., H. A. Mooney, D. D. Baldocchi, J. A. Berry, J. R. Ehleringer, C. B. Field, S. T. Gower, D. Y. Hollinger, J. E. Hunt, R. B. Jackson, S. W. Running, G. R. Shaver, W. Steffen, S. E. Trumbore, R. Valentini and B. Y. Bond, 2000. Carbon metabolism of the terrestrial biosphere: A multi-technique approach for improved understanding. Ecosystems 3, 115-130.

Challenger A. and J. Soberón, 2008. Los ecosistemas terrestres. In Capital natural de México (Conabio, Ed.). Comisión Nacional para el Conocimiento y Uso de la Biodiversidad, México, pp. 87-108.

Chapin F. S., P. A. Matson and H. A. Mooney, 2002. Principles of terrestrial ecosystem ecology. Springer, New York, 392 pp. 
Davidson E. A., P. A. Matson, P. M. Vitousek, R. Riley, K. Dunkin, G. García-Méndez and J. M. Maass, 1993. Processes regulating soil emissions of $\mathrm{No}_{\text {and }} \mathrm{N}_{2} \mathrm{O}$ in a seasonally dry tropical forest. Ecology 74, 130-139.

Fisher J. B., R. J. Whittaker and Y. Malhi, 2011. ET come home: potential evapotranspiration in geographical ecology. Global Ecol. Biogeogr. 20, 1-18.

Goulden M. L., J. W. Munger, S. M. Fan, B. C. Daube and S. C. Wofsy, 1996. Measurements of carbon sequestration by long-term eddy covariance: Methods and a critical evaluation of accuracy. Glob. Change Biol. 2, 169-182.

Greenland D., D. G. Goodin and C. Smith (Eds.), 2003. Climate variability and ecosystem response at longterm ecological sites. Oxford University Press, New York, $480 \mathrm{pp}$.

Hanson P. J., N. T. Edwards, C. T. Garten and J. A. Andrews, 2000. Separating root and soil microbial contributions to soil respiration: A review of methods and observations. Biogeochemistry 48, 115-146.

Harmon M. E., B. Bond-Lamberty, J. W. Tang and R. Vargas, 2011. Heterotrophic respiration in disturbed forests: A review with examples from North America. J. Geophys. Res.-Biogeo. 116, doi:10.1029/ 2010JG001495.

Hastings S. J., W. C. Oechel and A. Muhlia-Melo, 2005. Diurnal, seasonal and annual variation in the net ecosystem $\mathrm{CO}_{2}$ exchange of a desert shrub community (Sarcocaulescent) in Baja California, Mexico. Glob. Change Biol. 11, 927-939.

Heimann M. and M. Reichstein, 2008. Terrestrial ecosystem carbon dynamics and climate feedbacks. Nature 451, 289-292.

Hey T., S. Tansley and K. Tolle (Eds.), 2009. The fourth paradigm: data-intensive scientific discovery. Microsoft Research, Redmond, WA, 284 pp.

IPCC, 2007. Climate change 2007: The physical science basis. Contribution of Working Group I to the Fourth Assessment Report of the Intergovernmental Panel on Climate Change (S. Solomon, D. Qin, M. Manning, Z. Chen, M. Marquis, K. B. Averyt, M. Tignor and H. L. Miller, Eds.). Cambridge University Press, Cambridge, United Kingdom and New York, 996 pp.

Jung M., M. Reichstein, P. Ciais, S. I. Seneviratne, J. Sheffield, M. L. Goulden, G. Bonan, A. Cescatti, J. Chen, R. de Jeu, A. J. Dolman, W. Eugster, D. Gerten, D. Gianelle, N. Gobron, J. Heinke, J. Kimball, B. E. Law, L. Montagnani, Q. Mu, B. Mueller, K. Oleson, D. Papale, A. D. Richardson, O. Roupsard, S. Running, E. Tomelleri, N. Viovy, U. Weber, C. Williams, E. Wood, S. Zaehle and K. Zhang, 2010. Recent decline in the global land evapotranspiration trend due to limited moisture supply. Nature 467, 951-954.
Law B. E., T. J. Arkebauer, J. L. Campbell, J. Chen, O. Sun, M. Schwartz, C. van Ingen and S. Verma, 2008. Terrestrial carbon observations: Protocols for vegetation sampling and data submission. Global Terrestrial Observing System, FAO, Rome, 88 pp.

Le Quéré C., M. R. Raupach, J. G. Canadell, G. Marland, L. Bopp, P. Ciais, T. J. Conway, S. C. Doney, R. Feely, P. Foster, P. Friedlingstein, K. Gurney, R. A. Houghton, J. I. House, C. Huntingford, P. Levy, M. R. Lomas, J. Majkut, N. Metzl, J. P. Ometto, G. P. Peters, I. C. Prentice, J. T. Randerson, S. W. Running, J. L. Sarmiento, U. Schuster, S. Sitch, T. Takahashi, N. Viovy, G. R. van der Werf and F. I. Woodward, 2009. Trends in the sources and sinks of carbon dioxide. Nat. Geosci. 2, 831-836.

Mahecha M. D., M. Reichstein, N. Carvalhais, G. Lasslop, H. Lange, S. I. Seneviratne, R. Vargas, C. Ammann, M. A. Arain, A. Cescatti, I. A. Janssens, M. Migliavacca, L. Montagnani and A. D. Richardson, 2010. Global convergence in the temperature sensitivity of respiration at ecosystem level. Science 329, 838-840.

Masek J. G., W. B. Cohen, D. Leckie, M. A. Wulder, R. Vargas, B. de Jong, S. Healey, B. Law, R. Birdsey, R. A. Houghton, D. Mildrexler, S. Goward and W. B. Smith, 2011. Recent rates of forest harvest and conversion in North America. J. Geophys. Res.-Biogeo., 116, G00K03, doi:10.1029/2010JG001471.

Millennium Ecosystem Assessment, 2005. Ecosystems and human well-being: synthesis. Island Press, Washington, D.C., 139 pp.

Mittermeier R. A. and M. C. Goettsch, 1997. Megadiversity: Earth's biologically wealthiest nations. 1st English ed. CEMEX, Mexico, 501 pp.

Papale D., M. Reichstein, M. Aubinet, E. Canfora, C. Bernhofer, W. Kutsch, B. Longdoz, S. Rambal, R. Valentini, T. Vesala and D. Yakir, 2006. Towards a standardized processing of Net Ecosystem Exchange measured with eddy covariance technique: algorithms and uncertainty estimation. Biogeosciences 3, 571-583.

Pérez-Ruiz E. R., J. Garatuza-Payán, C. J. Watts, J. C. Rodríguez, E. A. Yépez and R. L. Scott, 2010. Carbon dioxide and water vapour exchange in a tropical dry forest as influenced by the North American Monsoon System (NAMS). J. Arid. Environ. 74, 556-563.

Pumpanen J., P. Kolari, H. Ilvesniemi, K. Minkkinen, T. Vesala, S. Niinisto, A. Lohila, T. Larmola, M. Morero, M. Pihlatie, I. Janssens, J. C. Yuste, J. M. Grunzweig, S. Reth, J. A. Subke, K. Savage, W. Kutsch, G. Ostreng, W. Ziegler, P. Anthoni, A. Lindroth and P. Hari, 2004. Comparison of different chamber techniques for measuring soil $\mathrm{CO}_{2}$ efflux. Agr. Forest. Meteorol. 123, 159-176. 
Reimer J. J., R. Vargas, S. V. Smith, R. Lara-Lara, G. Gaxiola-Castro, M. Hernández-Ayón, A. Castro, M. Escoto-Rodríguez and J. Martínez-Osuna. Air-sea $\mathrm{CO}_{2}$ fluxes in the near-shore and inter-tidal zones influenced by the California current. J. Geophys. Res.-Oceans, in review. Richardson A. D., T. A. Black, P. Ciais, N. Delbart, M. A. Friedl, N. Gobron, D. Y. Hollinger, W. L. Kutsch, B. Longdoz, S. Luyssaert, M. Migliavacca, L. Montagnani, J. W. Munger, E. Moors, S. L. Piao, C. Rebmann, M. Reichstein, N. Saigusa, E. Tomelleri, R. Vargas and A. Varlagin, 2010. Influence of spring and autumn phenological transitions on forest ecosystem productivity. Philos. T. Roy. Soc. B 365, 3227-3246.

SMAGDF, 2008. Inventario de emisiones de contaminantes criterio de la Zona Metropolitana del Valle de México. Secretaria del Medio Ambiente, Gobierno del Distrito Federal, Mexico, 160 pp.

Thomey M. L., S. L. Collins, R. Vargas, J. E. Johnson, R. F. Brown, D. O. Natvig and M. T. Friggens, 2011. Effect of precipitation variability on net primary production and soil respiration in a Chihuahuan desert grassland. Glob. Change Biol. 17, 1505-1515.

Vargas R. and M. F. Allen, 2008. Diel patterns of soil respiration in a tropical forest after hurricane Wilma. J. Geophys. Res.-Biogeo. 113, G03021, doi:10.1029/ 2007 jg000620.

Vargas R., M. S. Carbone, M. Reichstein and D. D. Baldocchi, 2011a. Frontiers and challenges in soil respiration research: from measurements to model-data integration. Biogeochemistry 102, 1-13.

Vargas R., D. D. Baldocchi, M. Bahn, P. J. Hanson, K. P. Hosman, L. Kulmala, J. Pumpanen and B. Yang, 2011b. On the multi-temporal correlation between photosynthesis and soil $\mathrm{CO}_{2}$ efflux: reconciling lags and observations. New Phytol. 191, 1006-1017.

Vargas R., 2012. How a hurricane disturbance influences extreme $\mathrm{CO}_{2}$ fluxes and variance in a tropical forest. Environ. Res. Lett. 7, 035704, doi:10.1088/17489326/7/3/035704.

Vargas R., H. W. Loescher, T. Arredondo, E. Huber-Sannwald, R. Lara-Lara and E. A. Yepez, 2012a. Opportunities for advancing carbon cycle science in Mexico: Toward a continental scale understanding. Environ. Sci. Policy 21, 84-93.
Vargas R., S. L. Collins, M. L. Thomey, J. E. Johnson, R. F. Brown, D. O. Natvig and M. T. Friggens, 2012b. Precipitation variability and fire influence the temporal dynamics of soil $\mathrm{CO}_{2}$ efflux in an arid grassland. Glob. Change Biol. 18, 1401-1411.

Velasco E., S. Pressley, E. Allwine, H. Westberg and B. Lamb, 2005. Measurements of $\mathrm{CO}_{2}$ fluxes from the Mexico City urban landscape. Atmos. Environ. 39, 7433-7446.

Velasco E., S. Pressley, R. Grivicke, E. Allwine, T. Coons, W. Foster, B. T. Jobson, H. Westberg, R. Ramos, F. Hernandez, L. T. Molina and B. Lamb, 2009. Eddy covariance flux measurements of pollutant gases in urban Mexico City. Atmos. Chem. Phys. 9, 7325-7342.

Velasco E. and M. Roth, 2010. Cities as net sources of $\mathrm{CO}_{2}$ : Review of atmospheric $\mathrm{CO}_{2}$ exchange in urban environments measured by eddy covariance technique. Geog. Compass 4, 1238-1259.

Velasco E., S. Pressley, R. Grivicke, E. Allwine, L. T. Molina and B. Lamb, 2011. Energy balance in urban Mexico City: observation and parameterization during the MILAGRO/MCMA-2006 field campaign. Theor. Appl. Climatol. 103, 501-517.

Vivoni E. R., H. A. Moreno, G. Mascaro, J. C. Rodríguez, C. J. Watts, J. Garatuza-Payán and R. L. Scott, 2008. Observed relation between evapotranspiration and soil moisture in the North American monsoon region. Geophys. Res. Lett. 35, L22403, doi:10.1029/2008GL036001.

Vivoni E. R., C. J. Watts and D. J. Gochis, 2010. Land surface ecohydrology of the North American monsoon system. Preface. J. Arid Environ. 74, 529-530.

Watts C. J., R. L. Scott, J. Garatuza-Payán, J. C. Rodríguez, J. H. Prueger, W. P. Kustas and M. Douglas, 2007. Changes in vegetation condition and surface fluxes during NAME 2004. J. Climatol. 20, 1810-1820.

Yépez E. A. and D. G. Williams, 2009. Precipitation pulses and ecosystem carbon and water exchange in arid and semiarid environments. In Biophysical plant ecophysiology: A tribute to Park S. Nobel (E. de la Barrera and W. Smith, Eds.). Universidad Nacional Autónoma de México, 440 pp. 